\title{
Toxicological Findings in Two Fatal Cases of Ingestion of Valproic Acid
}

\author{
SANTOSH R. KOTE*, MANOJ R. BHANDARKAR and NITIN L. CHUTKE \\ Department of Toxicology, Regional Forensic Science Laboratory, Home Department, State \\ of Maharashtra, Dhantoli, Nagpur - 440012. India \\ santosh.kote27@gmail.com
}

Received 28 July 2016 / Accepted 3 September 2016

\begin{abstract}
The case history and toxicological findings of two fatal cases of valproic acid are presented. Valproic acid extracted from visceral organs (Viscera I - Stomach, Intestine and its contents and Viscera II - pieces of Heart, Lung, Liver, Kidney and Spleen) was qualitatively determined by thin layer chromatography, chemical test and Gas chromatography, while quantitative analysis was done by gas chromatography. The qualitative results obtained from different analytical techniques were in good agreement. Quantitative determination by gas chromatography (GC) yielded the high concentration of valproic acid in Viscera I and Viscera II samples. In Case 1, toxicological analysis by GC yielded valproic acid concentration $131.17 \mathrm{mg}$ in Viscera I and $67.78 \mathrm{mg}$ in Viscera II per $100 \mathrm{~g}$, whereas in Case 2, Viscera I and Viscera II showed $69.29 \mathrm{mg}$ and $4.87 \mathrm{mg}$ per $100 \mathrm{~g}$ Valproic acid concentration respectively. The present finding far exceeds those associated with valproate therapy and similar to the limited valproate disposition data reported in prior fatal overdoses.
\end{abstract}

Keywords: Valproic acid, Viscera, Fatal cases, Gas chromatography, Forensic toxicology

\section{Introduction}

Valproic acid (VPA) has been used since 1967 as an anticonvulsant drug. The drug is also used for the treatment of various forms of epilepsy and in the manic depressive phase of bipolar disorders. Daily oral doses range from 250 to $2500 \mathrm{mg}$ and oral bioavailability of Valproic acid approaches $100 \%{ }^{1}$. Adverse reactions associated with valproic acid therapy include vomiting, nausea, sedation, weakness and tremor. Although VPA is generally considered a safe and well-tolerated drug, rare but serious complications may occur in some patients, such as hepatic failure, pancreatitis, thrombocytopenia, and hyperammonemic encephalopathy ${ }^{2,3}$. Central nervous system toxicity with symptoms varying from drowsiness to coma and cerebral edema is the most frequent effect of overdose. Respiratory failure has been observed in all fatal cases ${ }^{4}$. Fatal intoxication case with valproic acid disposition was reported in literature ${ }^{5}$. Salomone et $a .^{6}{ }^{6}$ studied in detail a fatal case of simultaneous ingestion of Mirtazapine, Escitalopram and Valproic acid. We report here two fatal cases of 
valproic acid overdose. Qualitative identification of valproic acid was done by chemical test and thin layer chromatography; while concentration in visceral samples was analyzed by gas chromatography. Case findings were compared to previous fatalities.

\section{Case 1}

In the case, a 32 year-old male leave for hospital and not returned at home. Next day his body was found in a farm with bleeding from his right ear. The police officials seized from his pant pocket, five tablet strip of Valprol-CR 300 (200 mg of sodium valproate and $87 \mathrm{mg}$ of valproic acid), out of which only two tablets were intact and five tablet strip of Pan 40 (40 mg of Pantoprazole) out of which only one tablet was intact; suggesting the occurrence of drug-related suicidal death. During the autopsy, no evidence of natural disease or trauma was found for this death. In order to determine whether massive drug consumption might have caused lethal intoxication, visceral samples (Viscera I - Stomach, Intestine and its contents and Viscera II - pieces of Heart, Lung, Liver, Kidney and Spleen) was collected for toxicological analysis.

\section{Case 2}

A deceased was a 48 year-old male with history of mental disorder found dead in his home. During further investigation, a packet of zinc phosphide, aluminium phosphide, four tablets of divalpro XR $1 \mathrm{~g}$ and one plastic bottle of immunax syrup were seized from scene of crime by police authority. In order to know the exact cause of death, visceral samples were preserved for toxicological analysis.

\section{Experimental}

All reagents were of analytical reagent grade purchased from S.D. Fine-Chem Ltd., Mumbai, India.

\section{Extraction of valproic acid from visceral material}

About $50 \mathrm{~g}$ viscera containing valproic acid was taken. Material was cut into fine pieces and minced carefully; $50 \mathrm{~mL}$ diethyl ether was added. The contents were kept with stirring for 30 minute and then filtered; the aqueous layer was separated and re-extracted with diethyl ether. Organic layer was dried over anhydrous sodium sulphate and the solvent was allowed to evaporate. The residues were used for further analysis.

\section{Thin layer chromatography}

For Thin layer chromatography, precoated TLC plates (Silica gel $60 \mathrm{~F}_{254}$, Merck Ltd., Germany) were used. Dichloromethane diethyl ether (1:1, by volume) mixture was used as solvent system for Valproic acid residues. The samples were spotted on TLC plates with fine capillary tubes along with pure valproic acid as the standard. The plates were dried and the chromatogram was developed in a presaturated tank containing the solvent system as mentioned above. After developing the plates, the solvent front (distance travelled by the solvent) was immediately marked and the extra solvent was evaporated (dried) in fume hood. The plates were then sprayed with aqueous bromocresol green reagent and aqueous ferric chloride solution. A spot with $R_{\mathrm{f}} 0.68$ was clearly visible.

\section{Chemical Test}

To a $1.0 \mathrm{~mL}$ of the test solution, $2.0 \mathrm{~mL}$ of dilute sodium hydroxide solution, $2.0 \mathrm{~mL}$ distilled water and $1.0 \mathrm{~mL} 10 \%$ cobalt nitrate solution were added. A bluish violet precipitate was formed; which dissolves in dichloromethane. 


\section{Gas chromatography}

Analyses were performed on DANI Master GC equipped with Flame Ionization Detector (FID). Chromatography was performed on DANI D N-5 capillary column $(30 \mathrm{mx} 0.25 \mathrm{~mm}$ i. d., $0.25 \mu \mathrm{m}$ film thickness). Injector and detector temperature was $220{ }^{\circ} \mathrm{C}$ and $230{ }^{\circ} \mathrm{C}$ respectively. Gas flow rates were as follows: Nitrogen carrier gas, $40 \mathrm{~mL} / \mathrm{min}$; hydrogen, $20 \mathrm{~mL} / \mathrm{min}$ and air, $300 \mathrm{~mL} / \mathrm{min}$ (Figure 1 \& 2).

\section{Results and Discussion}

The results of the toxicological analysis by these different procedures are in good agreement. In Case 1, Viscera I (Stomach, Intestine and its contents) and Viscera II (pieces of Heart, Lung, Liver, Kidney and Spleen) showed $131.17 \mathrm{mg}$ and $67.78 \mathrm{mg}$ of valproic acid per $100 \mathrm{~g}$ of viscera (Figure $1 \& 2$ ). In this case deceased was also found ethyl alcohol positive. Which comprehensible that deceased consumed higher dose of valproic acid under the influence of ethyl alcohol.

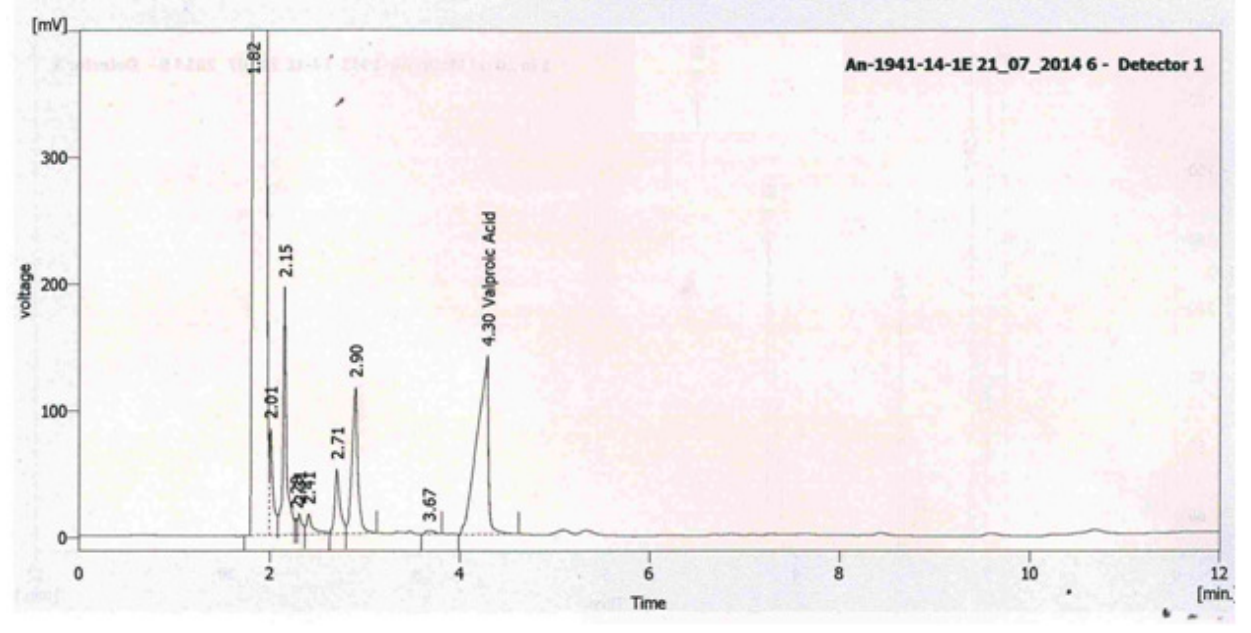

Figure 1. Chromatogram of Viscera I (Case 1)

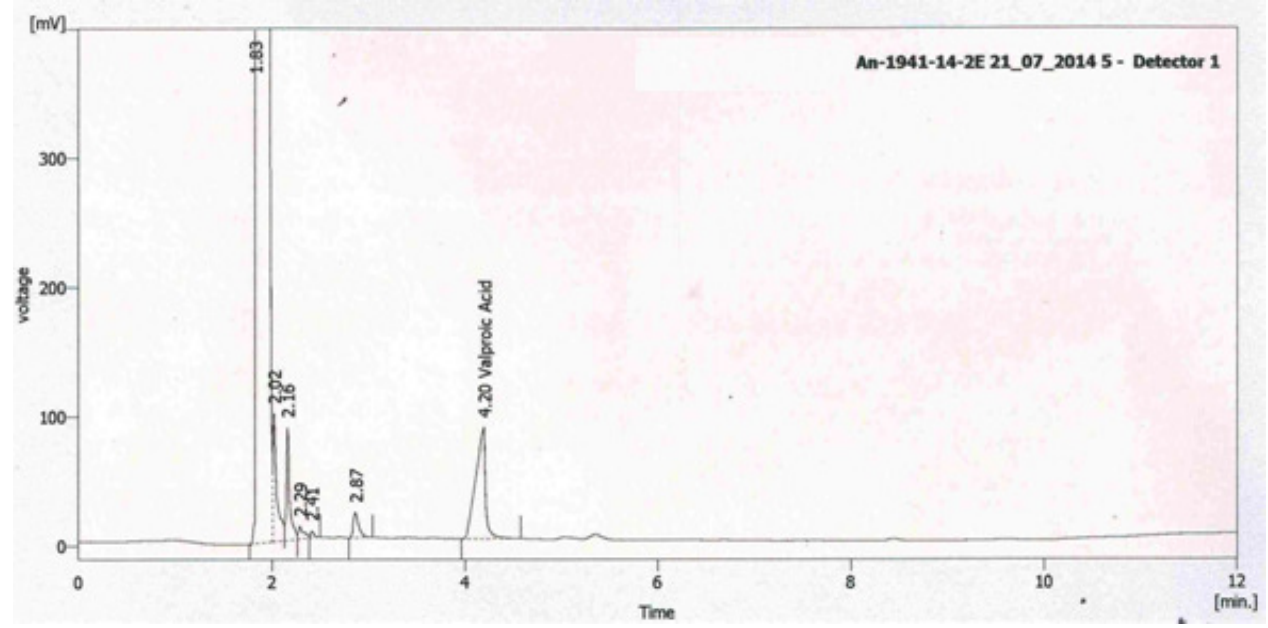

Figure 2. Chromatogram of Viscera II (Case 1) 
In case 2, valproic acid concentration was found to be $69.29 \mathrm{mg}$ and $4.87 \mathrm{mg}$ per $100 \mathrm{~g}$ in Viscera I and Viscera II. The tests for rodenticides zinc phosphide, aluminium phosphide and ethyl alcohol are negative, even though these non biological articles were seized from the crime scene.

\section{Conclusion}

Based on the circumstances surrounding the presented deaths and high tissue concentrations of valproic acid in the present study, the cause of death was attributed to an overdose of valproic acid. The cases presented demonstrate the importance of toxicological analysis during investigation, apparently negative in routine examinations.

\section{Acknowledgement}

The Authors are thankful to Mr. B. B. Daundkar, Director, Directorate of Forensic Science Laboratories, State of Maharashtra, Mumbai, India, for helpful discussion and suggestions.

\section{References:}

1. Baselt R C, Disposition of Toxic Drugs and Chemicals in Man. $7^{\text {th }}$ Edition, Biomedical Publications. Foster city, CA, 2004.

2. Valproic acid. In: Drugdex system [database online]. Greenwood Village (CO): Thomson Healthcare; 2008.

3. Lheureux P E, Penaloza A, Zahir S and Gris M, Crit Care., 2005, 9, 431-140.

4. Anderson G O and Ritland S, J Toxicol Clin Toxicol., 1995, 33(3), 279-284; DOI: $10.3109 / 15563659509018000$

5. Poklis A, Poklis J L, Trautman D, Treece C, Backer R and Harvey C M, J Anal Toxicol., 1998, 22(6), 537-540; DOI:10.1093/jat/22.6.537

6. Salomone A, Corcia D D, Gerace E and Vincenti M, J Anal Toxicol., 2011, 35(7), 519-523; DOI:10.1093/anatox/35.7.519 